\title{
The challenges and future of oral drug delivery: An interview with David Brayden
}

\begin{abstract}
David Brayden speaks to Hannah Makin, Commissioning Editor: David Brayden is a Full Professor (Advanced Drug Delivery) at the School of Veterinary Medicine, University College Dublin (UCD) and also a Fellow of the UCD Conway Institute. Following a PhD in Pharmacology at the University of Cambridge, UK (1989), and a postdoctoral research fellowship at Stanford University, CA, USA, he set up Elan Biotechnology Research's in vitro pharmacology laboratory in Dublin (1991). At Elan, he became a senior scientist and project manager of several of Elan's joint-venture drug delivery research collaborations with US biotech companies. In 2001, he joined UCD as a lecturer in veterinary pharmacology and was appointed Associate Professor in 2006 and Full Professor in 2014. He was a Director of the Science Foundation Ireland Research Cluster (The Irish Drug Delivery Research Network) from 2007 to 2013, is a Deputy Coordinator of an FP7 Consortium on oral peptides in nanoparticles ('TRANS-INT', 2012-2017), and is a Co-Principal Investigator in 'CURAM', Science Foundation Ireland's new Centre for Medical Devices (2014-2020 [1]). He was made a Fellow of the Controlled Release Society in 2012. He is the author or co-author of $>200$ research publications and patents. D Brayden serves on the Editorial Advisory Boards of Drug Discovery Today, European Journal of Pharmaceutical Sciences, Advanced Drug Delivery Reviews and the Journal of Veterinary Pharmacology and Therapeutics, and is an Associate Editor of Therapeutic Delivery. D Brayden works as an independent consultant for drug delivery companies.
\end{abstract}

First draft submitted: 6 October 2016; Accepted for publication: 11 October 2016; Published online: 8 November 2016

Keywords: epithelial drug transport • intestinal epithelia • nanomedicines $\bullet$ oral peptides

How did you first get involved in the field of drug delivery \& specifically oral drug delivery?

It was a moment of opportunism when I was a postdoc working on intestinal epithelia at Stanford in 1990. I was a Cambridge University-trained epithelial electrophysiologist and had done my ion transport $\mathrm{PhD}$ and postdoctoral work on the chloride transport defect in cystic fibrosis and I knew a lot about intestinal and airway transport of ions. I distinctly remember going to a cystic fibrosis conference in the USA in 1990 and realizing that once the gene had been discovered
(1989) that it was likely that much of the ion channel work had already been completed (I was wrong about that) and that the way was clear for the molecular biologists and gene therapists to dominate that field. I felt that my days as a fundable epithelial ion transporter were numbered. At the same time I got interested in Alza Drug Delivery up to the road from Stanford and I realized that I could work on drug delivery using many of the same bioassays I had learned for ion transport studies. As it happened, the Irish homing gene kicked in and I end up going to Elan Drug Delivery in 1991 for what was

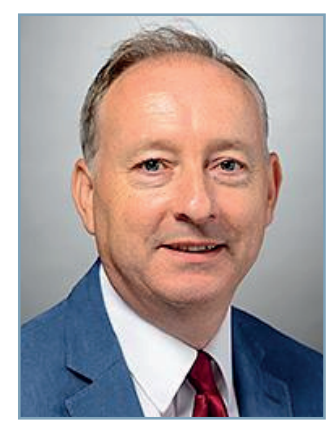

David J Brayden School of Veterinary Medicine, University College Dublin, Dublin, Ireland David.Brayden@ucd.ie 
initially a 12-month research job, and the only one in biology in Ireland in that depressing time. I went back to Dublin and set up Elan's in vitro pharmacology research laboratory in Trinity College under a visionary boss who basically gave me a budget and told me to go and hire some PhDs and invent things around how to make non-injected formulations of peptides. I spent 10 years at Elan before moving back into academia to University College Dublin (UCD) in 2001 and they told me that I could continue to research many of my interests in oral drug delivery if I could convince funders to pay for it and the proviso was that I had to teach Pharmacology to veterinary and science students.

\section{Q Can you update us on some of your research group's current work?}

The group is about four to five $\mathrm{PhDs}$ and two postdocs and a technician at any one time, depending on the state of funding. Of late, I have moved into some new areas (for me), where I have funding from Science Foundation Ireland for research in medical devices and have a $\mathrm{PhD}$ project looking at devices that can increase peptide fluxes across models of the buccal epithelium. I also work in an area of interest for the food industry, and have another PhD student investigating how to improve oral absorption of some exciting small peptides with useful pharmacology, originally found in milk and chicken muscle. The food industry has some very exciting molecules emerging from screening peptides from hydrolysates, but it is more restricted in the types of ingredients and formulations it uses. We have been examining permeation mechanisms of such peptides and working out what types of formulation assistance might be helpful. My group is just competing its role as part of a large EU consortium, TRANS-INT, whose aim was to entrap therapeutic peptides in nanoparticles and to test them in preclinical models. We supplied an interesting silica-based nanoparticle and also carried out a lot of the in vivo screening to tell which particles might be the most interesting. TRANS-INT just completed a Special Issue of Advanced Drug Delivery Reviews from our consortium and I believe that this will be a significant output for the field. Finally, I have direct- and co-funded oral drug delivery collaborations with both the pharma and food industries, and current partners include Gattefosse (Lyon), Jazz Pharma (Dublin), Anabio (Dublin) and Sanofi (Montpellier).

Is there an area of research in your field of work that you are particularly excited about at the moment?

I am part of the UCD Veterinary School and I like to have at least one veterinary-related project on the go. We have injected a novel anti-inflammatory nano -particle construct into the joints of horses that have been primed with lipopolysaccharide as an acute model of inflammation. The process of scaling the production of the nanoparticle from a mouse study (published in the Journal of Controlled Release) to the equine system involved many research actors and one of the most challenging aspects was ensuring we had sterile nanoparticles and would not be putting the horses at risk. We are still in the middle of this project and will be optimizing a nanoparticle construct, but I feel that this type of research has a lot of mileage in terms of designing particles that are retained in the joint and whose composition can compete with the relatively poor injectable therapies of steroids and hyaluronic acid for osteoarthritis.

You mentioned in a recent review article that oral drug delivery faces the challenge of overcoming suboptimal physicochemical properties of the intestinal epithelium \& enzymatic/chemical degradation of peptides in the intestine. Do you think these challenges can be easily overcome with further research, \& if so, how?

I see this field maturing in that medicinal chemists are now providing stable peptides in macrocycle formats of about 1000-2000 Da. Previously, we had to rely on peptides handed down as very large molecular weight structures designed for parenteral injection, so this is a big change. We now see fairly standard formulations of enhancer-based systems being retested in human trials with reasonably stable peptides that have a long half and are very potent, again progress that made many people think again about oral peptides. If someone had said 10 years ago that an oral peptide could be a commercial product with $<5 \%$ bioavailability, the project would have been shut down, but now we see that peptides are being made more cheaply, are ever more potent, so that large pharma now consider this a reasonable proposition.

Q Your recent research suggests that intestinal permeation enhancers may have a critical role in improving the oral delivery of therapeutics. How do you think further research into these enhancer molecules will have an impact in the field of drug delivery?

Intestinal permeation enhancers have a pretty checkered history due to lack of efficacy in clinical trials and concerns over toxicity. We and others have devoted a lot of effort into seeking out the best ones, finding out their mechanism of action in vitro and in vivo, and also in taking the next step of working them into proper oral 
dosage forms. If you look at the 20 or so technologies in clinical trials for oral peptides, the majority have built in a permeation enhancer component, while the rest use nanotechnology in the as yet unproven hypothesis that the latter will be internalized by epithelia in enough quantities to give a pharmacological response. Gradually we are working out a therapeutic index for some of the key enhancers but, overall, we have not seen much evidence of toxicity in terms of inadvertently allowing permeation of bystander pathogens.

\section{What challenges do you think must first} be overcome for the successful use of such permeation enhancers in medicine?

Some of the best enhancers including medium chain fatty acids, acyl carnitines and bile salts have been in Phase II trials without many toxicity concerns to date, but the challenge is whether the best enhancer can truly achieve $5 \%$ oral bioavailability without a commensurate increase in epithelial damage. There is a confounding problem, in that the industry understandably is quite conservative and risk-averse, so the interest in enhancers is largely restricted to those that are known excipients, have generally regarded as safe status at the US FDA, or at a minimum have a long history of safe use in man.

\section{You have also undertaken research over} the recent years investigating the relationship between nanoparticles \& oral therapeutics. What do you think lies in the future for nanoparticles in oral drug therapy?

When I was in Elan in the late 1990s, the Nanocrystal ${ }^{\circledR}$ technology was in full swing and was a very successful nanotechnology involving solubilizing small molecules using quite a low-tech milling and blending protocol. That technology was commercially successful, scalable and could be transferred to partner laboratories. On the other side of the company were the experts in making high-tech receptor-targeted peptide-loaded particles, but the problem was that they could not be made the same way twice and would work in one preclinical study, and then fail in the next. So this very elegant solution failed and I learned a lot about the attributes such a technology requires in order to move through development by just looking across at the success of the 'blender' guys! In the TRANS-INT consortium, we still work on untargeted particles containing peptides, but the jury is out on whether these are taken up in sufficient quantities by the human small intestine in vivo; if they are, then we have to seriously look at the toxicity potential; if they are not, then we have to justify why we need nanoparticles as a tool of protection with a capacity for local release in the intestine, when we have many simpler formulation ways to do that.
What would you consider your most important achievement to date?

Survival as a funded researcher for 30 years! The many $\mathrm{PhDs}$ I have helped train is probably the most important legacy of any academic as you are passing knowledge and hopefully good ways to do science through to the next wave of researchers, be they heading to academia or industry. My favorite paper is the one I have just seen the galley proofs of, as I am usually on to the next project quite quickly. If I had to pick one that had a lot of impact, it would be the 2013 paper in Journal of Controlled Release on the joint-injectable anti-inflammatory calcitonin-hyaluronic acid nanoparticle, as I had to bring a multidisciplinary team together from three different institutions to make the particle, to look at the in vitro pharmacology, and then to test it in a really specialized model of murine inflammatory arthritis [2].

\section{What words of advice would you give to a} young scientist envisaging a career in this area?

I think that doing a really productive postdoc overseas in a top lab after a $\mathrm{PhD}$ can prepare someone well for at least having the option of staying in academia or moving to industry. Another thing I have learned during my career to date is that it is useful to find areas of research that are perhaps not so well trodden and where you can stand out from the crowd. Of course, it is good to keep people guessing, when I was in Elan, I was regarded as an academic because I published and had academic collaborations (these were very important in my transition to academia). In UCD, they have viewed me largely as an applied pharmaceutics researcher linked to industry, while the Veterinary School still does not quite know what to make of me! Finally, the drug delivery field tends to be quite cyclical in its interests, so it is important to stick to your guns and try to answer important hypothesis-driven questions. Even if your research area is not in vogue at present, like oral peptides in 2000 , it may well be shortly.

\section{Disclaimer}

The opinions expressed in this interview are those of the interviewee and do not necessarily reflect the views of Future Science Ltd.

\section{Financial \& competing interests disclosure}

DJ Brayden has received direct research grants sponsored by Gattefosse, Sanofi, and Jazz Pharmaceuticals, and an industry partnership grant from the Irish Research Council with Anabio Ltd. DJ Brayden has no other relevant affiliations or financial involvement with any organization or entity with a financial interest in or financial conflict with the subject mat- 
ter or materials discussed in the manuscript apart from those disclosed.

\section{References}

1 Centre for research in medical devices. www.curamdevices.ie
No writing assistance was utilized in the production of this manuscript.

2 Ryan SM, McMorrow J, Umerska A et al. An intra-articular salmon calcitonin-based nanocomplex reduces experimental inflammatory arthritis. J. Control. Release 167(2), 120-129 (2013). 